
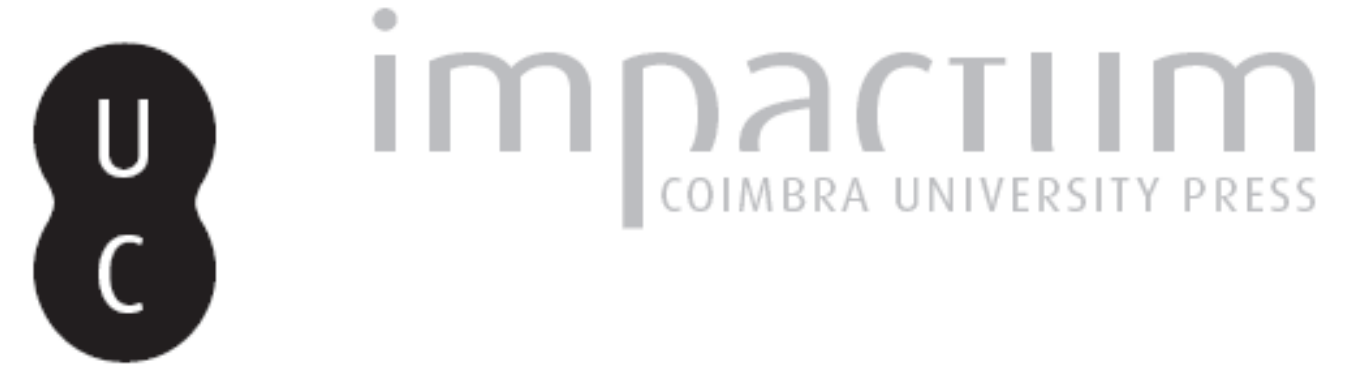

\title{
Direito dos atores globais coletivos
}

\section{Autor(es): $\quad$ Rudiger, Dorothee Susanne}

Publicado por: Faculdade de Direito da Universidade de Coimbra

URL persistente:

URl:http://hdl.handle.net/10316.2/24748

DOI:

http://dx.doi.org/10.14195/0870-4260_51_5

Accessed : $\quad$ 26-Apr-2023 12:54:26

A navegação consulta e descarregamento dos títulos inseridos nas Bibliotecas Digitais UC Digitalis, UC Pombalina e UC Impactum, pressupõem a aceitação plena e sem reservas dos Termos e Condições de Uso destas Bibliotecas Digitais, disponíveis em https://digitalis.uc.pt/pt-pt/termos.

Conforme exposto nos referidos Termos e Condições de Uso, o descarregamento de títulos de acesso restrito requer uma licença válida de autorização devendo o utilizador aceder ao(s) documento(s) a partir de um endereço de IP da instituição detentora da supramencionada licença.

Ao utilizador é apenas permitido o descarregamento para uso pessoal, pelo que o emprego do(s) título(s) descarregado(s) para outro fim, designadamente comercial, carece de autorização do respetivo autor ou editor da obra.

Na medida em que todas as obras da UC Digitalis se encontram protegidas pelo Código do Direito de Autor e Direitos Conexos e demais legislação aplicável, toda a cópia, parcial ou total, deste documento, nos casos em que é legalmente admitida, deverá conter ou fazer-se acompanhar por este aviso.

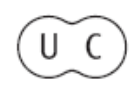




\section{UNIVERSIDADE DE COIMBRA \\ FACULDADE DE DIREITO}

BOLETIII DE CÊACCLS ECONÓNCACAS

VOLUME LI

$\begin{array}{llll}2 & 0 & 0 & 8\end{array}$

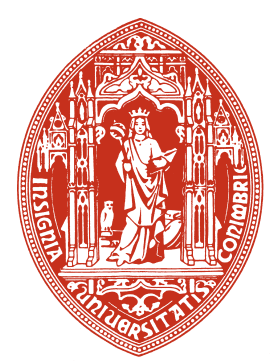

COIMBRA 


\section{DIREITO DOS ATORES GLOBAIS COLETIVOS}

\section{Following the Sun}

Numa jornada de trabalho típica em uma empresa mundial de prestação de serviços de informática, os empregados trabalham "desde o nascer ao pôr do sol", usando uma imagem do passar do tempo que remonta a uma época pré-moderna. ${ }^{1}$ Quando os trabalhadores nos estabelecimentos da empresa da Índia começam a trabalhar, o serviço da equipe brasileira tem que estar literalmente "em dia". Os trabalhadores varrem a noite para solucionar problemas com sistemas operacionais para clientes dos Estados Unidos e do resto do mundo. O trabalho em rede dos profissionais da informática dispensa, na maioria das vezes, que estes estejam "de corpo presente" nos estabelecimentos da empresa. Basta para a empresa equipá-los de um Note-book, um telefone Nextel e de um roteador para possibilitar a comunicação realizada em teleconferências globais: China, Índia, Brasil, Argentina, Estados Unidos... os nomes dos países são apenas alusão a lugares onde se trabalha e se ganha o pão com diferenças salariais gritantes. Com o sistema de home-office, de quebra, a

${ }^{1}$ Thompson, Edward Paul, ob. cit., em Past and Present. n. 38, 57-97. 
empresa economiza capital fixo gasto em infra-estrutura empresarial, isola os trabalhadores e dificulta, quando não impossibilita, sua organização sindical. ${ }^{2}$

Como a apresentação do caso já denota, o problema de muitas facetas do direito dos atores globais tem aqui um recorte nas relações de trabalho globais. Para se empreender uma análise das relações jurídicas globais no trabalho é necessário ter em conta tanto questões de ordem objetiva quanto de ordem subjetiva. O cenário global, seus atores e o direito que geram são, portanto, objetos centrais do presente estudo.

É necessário, em primeiro lugar, situar o direito dentro de seu contexto histórico. A globalização, tida como novo paradigma das ciências sociais, é focada aqui como um movimento do capital e, ao mesmo tempo, como um movimento político que põe em xeque a questão da cidadania. Constitui o pano de fundo de uma cultura que, para muitos, merece, nem que seja por falta de alternativa, o nome de "pós-moderna". Líquida, leve, esfarelada, esgarçada, desmanchada, a modernidade apresenta-se em crise nas belas artes, na ciência, na política e no direito ${ }^{3}$, questionando, criando e recriando nossos laços sociais, transformando nossa subjetividade, nossa maneira de olhar e de perceber o mundo. ${ }^{4}$ Mas nem tudo é leve e multicolorido nesse cenário. Se ainda há o que pode ser chamado de sociedade, pois já existem dúvidas quanto a isso, ${ }^{5}$ esta criou novos laços em rede. As novas possibilidades da informática, cuja expressão mais comum é a internet, revolucionaram não somente nossas relações de

${ }^{2}$ Antunes, Ricardo, Adeus ao Trabalho?, cit..

${ }^{3}$ Lyotard, Jean-François, cit., 69.

${ }^{4}$ Bauman, Zygmunt, Modernidade líquida, cit.; Forbes, Jorge. Você quer o que deseja?, cit.; Touraine, Alain, Um novo paradigma..., cit..

${ }^{5}$ Touraine, Alain, ob. cit.. 
trabalho, revolucionaram também nosso jeito de ser e abrigam, por outro lado, o perigo de uma sociedade de controle. ${ }^{6}$

Diante desse cenário, os atores coletivos globais merecem destaque como sujeitos capazes de formatar antigos e novos laços sociais na sociedade contemporânea. Redes empresariais, Estados, organizações internacionais, organizações não governamentais (ONGs) mundiais e sindicatos têm uma função política e jurídica a cumprir: a de representar interesses e de articular estes por um direito que foge das instâncias legislativas tradicionais. No entanto, esse novo direito produzido pelos atores coletivos globais suscita questões que levam ao limiar das teorias tradicionais sobre a validade da norma. Por isso, o presente estudo não tem a pretensão de ser concludente. Antes pelo contrário, reconhece que o direito circunscreve apenas um vácuo, uma anomia que pode ser chamada de estado de exceção. ${ }^{7}$ Além disso, diante do processo histórico em curso, nós, os atores globais contemporâneos, podemos estar cegos pela necessidade do agir corretamente, pela necessidade, enfim, de nossa práxis.

\section{Globalização: mudanças no cenário político- econômico}

A globalização contemporânea, isto é, a fase histórica na qual estamos inseridos no século XXI, foi construída a partir do cenário do segundo pós-guerra, e teve como grande ator o Welfare-State, que desempenhava, principalmente nos países capitalistas destruídos pela Segunda Grande Guerra, um papel de verdadeiro "vetor do progresso". 8

${ }^{6}$ Miller, Jacques Alain \& Milner, Jean-Claude, Você quer mesmo ser avaliado?, cit..

${ }^{7}$ Agamben, Giorgio, Estado de exceção, cit. .

${ }^{8}$ Roth, A.-N., "O direito em crise...", cit., 17. 
Característica não somente da política estatal, como também da administração de empresas, é o planejamento, ou, ao menos, a idéia de que com planejamento se poderia conquistar o futuro, o progresso. ${ }^{9}$

Na política, John Maynard Keynes e, na administração, Frederick Taylor e Henry Ford desenvolvem a idéia moderna do planejamento, que, com a visão voltada para o futuro, descarta o passado em prol da prosperidade. No Estado de Bem-Estar Social a prosperidade é, ao menos em tese, distribuída entre o capital e o trabalho. Um dos instrumento da distribuição de rendas do capitalismo é o direito do trabalho, que, aqui, cumpre sua função paradoxal de conquista de classe dos trabalhadores e de dispositivo que garante a ordem capitalista.

A negociação coletiva, embora expressão do movimento dos trabalhadores, não escapa a essa contradição. No contexto da política do welfare-state, constitui um poderoso instrumento de distribuição dos ganhos do capital com o crescimento da economia do pós-guerra. ${ }^{10}$ Vale mencionar que a política do Estado de Bem-Estar Social é levada a cabo pelo Estado nacional. A fase histórica do auge do welfare-state é marcada politicamente pela Guerra Fria, pela complexa emancipação política dos povos das antigas colônias imperialistas e por uma riqueza que permite a Eric Hobsbawm falar numa “época de ouro". ${ }^{11}$ No início dessa época dourada, na qual nem se cogitava a globalização da economia, é firmado o GATT (General Agreement on Trade and Tariffs), em 1948, o ano em que é também proclamada a Declaração Universal dos Direitos Humanos.

\footnotetext{
${ }^{9}$ Bauman, Zygmunt, ob. cit., 152 ss.

${ }^{10}$ Harvey, David, Condição pós-moderna..., cit., 129.

${ }^{11}$ Hobsbawm, Eric, Era dos extremos, cit., 223ss.
} 
No entanto, esse El Dorado do capitalismo do segundo pós-guerra durou pouco. O capitalismo sofre, durante os anos de 1960, uma crise de superacumulação que arrasta consigo o welfare state para uma crise financeira, e, no plano político-jurídico, para uma crise de legitimidade. O Estado torna-se devedor de suas promessas normativas não cumpridas. O rompimento unilateral dos Acordos de Bretton Woods, por parte dos Estados Unidos da América, inaugura, em 1973, uma nova época. Firmado durante a Segunda Guerra Mundial, em 1944, esse acordo estabelecia uma rígida política cambial, prevendo, dentre outras normas, restrições para a circulação da moeda fora das fronteiras dos estados nacionais.

A globalização, a nova possibilidade da circulação, principalmente da moeda americana, constitui uma saída para a crise do capitalismo que, a partir dos anos 1970, muda de figura. O domínio do capital financeiro, o investimento direto dos bancos nas actividades produtivas, a concorrência mundial pela desconstrução das barreiras alfandegárias, na Europa, nas Américas e no antigo Bloco Soviético, fazem parte desse novo cenário. ${ }^{12}$ Os Estados adotam os cânones da política neoliberal, inspirada nas teorias de Friedrich Hayeck e Milton Friedman. Estão em pauta a privatização de empresas públicas e a redução das prestações sociais, no seio de um Estado que volta à sua função primordial: a manutenção da ordem, além da representação dos interesses econômicos nacionais no mercado global.

No entanto, nem só o Estado se transforma. As empresas também passam por profundas transformações. As grandes empresas fordistas, instituições organizadas e administradas hierarquicamente em grandes estabelecimentos locais, estão,

${ }^{12}$ Chesnais, François, A mundialização do capital, cit. 
paulatinamente, cedendo a redes de empresas toyotistas. Diferentemente das empresas administradas na lógica do fordismo, as empresas toyotistas não se prendem ao local, a grandes estabelecimentos produtivos. Contratam um mínimo de trabalhadores polivalentes e, se necessário, serviços terceirizados para suprir a demanda de serviços especializados ou de serviços que dão conta de um eventual aumento da demanda dos bens produzidos. Tiram partido, principalmente, da diversidade das condições de trabalho existentes em cada empresa local que faz parte da organização em rede. ${ }^{13}$ A organização toyotista afeta as relações de trabalho, dispensando a grande massa de trabalhadores, presentes nas fábricas administradas pelos ditames do fordismo, dividindo seu "corpo", enfraquecendo suas organizações de classe. ${ }^{14}$ Do ponto de vista jurídico, a passagem do fordismo para o toyotismo implica a flexibilização das relações individuais e coletivas de trabalho. ${ }^{15}$

\section{Pós-modernidade: uma maneira de pensar e de perceber no século XXI}

Estamos comemorando 40 anos das revoltas estudantis de 1968, uma revolução que mudou a maneira de pensar e de perceber o mundo, tamanha a influência que os acontecimentos daquele ano exerceram sobre a cultura ocidental, acontecimentos que tomaram conta do mundo e que, de

${ }^{13}$ Cfr. op. cit., 104.

${ }^{14}$ Ricardo Antunes vê a emergência de uma nova "classe que vive do trabalho". Antunes, Ricardo, "A nova morfologia do trabalho...", cit., 213ss.

${ }^{15}$ Rudiger, Dorothee Susanne, "O direito do trabalho brasileiro no contexto da globalização”, cit., 165-170. 
certa maneira, já tinham sua precursora na revolução cultural da China, ocorrida a partir de 1966. As manifestações de inquietude juvenil, intelectual e operária, transformaram a política, a arte, a filosofia, a subjetividade e o direito, sem, no entanto, tocar na economia de mercado. Vivemos, graças aos múltiplos movimentos que se manifestaram a partir de 1968, numa época que, como já foi dito, por falta de outro termo, é chamada de pós-moderna.

Exemplos dessa revolução dos costumes na arte não faltam. As fronteiras entre o passado, o presente e o futuro se desfazem. Das sobras do passado, a arquitetura pós-moderna faz um novo estilo. Os fragmentos da história são recompostos em colagens. Transgressões entre a realidade e a virtualidade, entre o sonho e o cotidiano, entre a razão e a fantasia, entre o masculino e o feminino, entre ser humano e ser andróide, são tema em filmes, tais como Asas do Desejo, Blade Runner e Matrix. ${ }^{16}$ A nova estética, presente na arte pós-moderna, é apenas um dos sinais de que estamos diante de uma nova subjetividade que o psicanalista francês Jacques Lacan verificou, a partir das observações clínicas, já em 1963, quando em sua obra Nomes do pai constata a dissolução da chamada metáfora paterna. ${ }^{17} \mathrm{O}$ pai como grande referência cultural estava se multiplicando, as instituições sociais verticalizadas se pulverizando. $\mathrm{O}$ sujeito, antes orientado na família patriarcal, no estado nacional e na empresa hierarquizada, hoje passou a ser desorientado, desbussolado, apresentando novos sintomas, tais como o fracasso escolar, a toxicomania, a violência inusitada da nova criminalidade. ${ }^{18}$

O desafio cultural e jurídico é a busca de uma nova ética que independe do recurso às instâncias das autoridades

\footnotetext{
${ }^{16}$ Harvey, David, op. cit., 277ss.

${ }^{17}$ Lacan, Jacques, Des noms-du-père, ob. cit..

${ }^{18}$ Forbes, Jorge, "A clínica do homem desbussolado”, cit., 31-49.
} 
externa (presente no aparato punitivo do Estado) e interna (presente no que Sigmund Freud chama de superego) e assume responsabilidade diante do acaso, diante do futuro, diante do desconhecido, daquilo que foge à lógica, enfim, diante do que Jacques Lacan chama de "real". 19

$\mathrm{O}$ que fazer diante do "deserto do real" 20 não é somente a questão crucial na vida da personagem Neo no filme Matrix. Se as teses da filosofia pós-moderna que revolucionou o pensamento a partir dos ensinamentos de Jacques Lacan estiverem valendo, não haverá, na contemporaneidade pós-moderna, valores que resistam à denúncia de serem mero exercício de poder dos que produzem saber. Os paradigmas, os supremos valores do pensamento moderno são expressão ora de "poder simbólico" 21 , ora de "grandes narrativas" 22 . O belo na arte, a verdade na ciência, a emancipação na política e a justiça no direito cedem a "pequenas narrativas", ao pragmatismo dos detentores do poder de controlo no mercado.

Jacques Derrida desconstrói o direito, denunciando-o como campo de força em torno de um estado sem lei. Se houver justiça, esta situa-se fora da lei. Fora do alcance da força histórica que constitui o direito, a justiça está segura, pode sobreviver. ${ }^{23}$ É digno de nota que a filosofia pós-moderna encontra em Jürgen Habermas um grande crítico. Para o filósofo alemão da Escola de Frankfurt, o pensamento moderno não está enterrado, mas necessita resgatar uma das promessas da modernidade não cumpridas: a emancipação. ${ }^{24}$

${ }^{19}$ Forbes, Jorge, O princípio responsabilidade: do medo ao desejo, cit.

${ }^{20}$ Baudirllard, Jean, Simulacros e simulação, cit., 8.

${ }^{21}$ Bourdieu, Pierre, O poder simbólico, cit. 3.

${ }^{22}$ Lyotard, Jean-François, op. cit., 35 ss.

${ }^{23}$ Derrida, Jacques, Force de loi..., cit., 60.

${ }^{24}$ Cfr. Habermas, Jürgen, Der philosophische Diskurs der Moderne, cit., 11. Adorno, Theodor W. \& Horkheimer, Max, Dialética do esclarecimento..., cit.. 
No entanto, o que se observa é que, ao menos no que tange ao direito contemporâneo, a análise feita por Jean François Lyotard procede. Problemático é a transformação dessa análise num receituário político que vai ao encontro do neoliberalismo. ${ }^{25}$ Pelas observações feitas por Jean François Lyotard, o direito da grande narrativa da justiça cede ao direito das "pequenas narrativas" 26 : mais importante que a sentença, sempre insuficiente diante da expectativa de justiça, é o processo; a lei, genérica demais para abarcar as circunstâncias do cotidiano, cede ao contrato, à "lei entre as partes", como quer o art. 1134. ${ }^{\circ}$ do Código Napoleônico; não importando o resultado, o procedimento deve ser respeitado. O direito das pequenas narrativas é contratual e procedimental. $^{27}$

A passagem do direito moderno para o direito pós-moderno pode ser observada, por exemplo, no direito do trabalho, em vários aspectos. À fragmentação do corpo coletivo dos trabalhadores na passagem da empresa fordista para a empresa toyotista corresponde a fragmentação jurídica dos trabalhadores por sua contratação atípica. A forma típica de contratar trabalhadores, o emprego, tal como previsto nos $\operatorname{artigos} 2 .^{\circ}$ e $3 .^{\circ}$ da Consolidação das Leis do Trabalho brasileira, está cedendo paulatinamente a várias formas de contratação de trabalho. A procedimentalização do Direito do Trabalho, é levada a cabo pela negociação coletiva permanente não somente nas categorias, como no dia-a-dia das empresas. Não importando os resultados, se positivos ou negativos para os trabalhadores, a negociação coletiva permanente é um instrumento de flexibilização do Direito do

${ }^{25}$ Rudiger, Dorothee, "Transformações do direito do trabalho na pós-modernidade", cit..

${ }^{26}$ Lyotard, Jean-François, op. cit., 119.

${ }^{27}$ Rudiger, Dorothee, ult. op. cit. 
Trabalho, que o adapta às contingências da globalização. E se, por um lado, o desmanche do "grande outro" da instituição fordista abre chances principalmente para os trabalhadores mais qualificados que podem tornar-se autônomos, por outro lado, a competição no mercado globalizado vai na contramão da solidariedade. A reorganização do mercado de trabalho e o esfarelamento das modernas relações de trabalho colocam aos sindicatos a necessidade de busca de novas propostas de organização. A unidade dos trabalhadores na diversidade é, diante de novas formas de exercício do trabalho, o grande desafio do século XXI. É imperioso que as organizações sindicais façam frente às novas formas de fazer valer os interesses do capital, façam frente à sua organização em rede.

\section{A sociedade em rede}

Se, por um lado, assistimos à desintegração das instituições tradicionais da sociedade, tais como a família patriarcal, o Estado e a empresa, vivemos, por outro lado, sua conexão em rede. A tecnologia da informação presente principalmente na internet possibilita uma reorganização dos que foram desintegrados: familiares, amigos, trabalhadores, empresas. Estas últimas vivem, atuando no mercado mundial, um verdadeiro paradoxo. Concorrendo entre si, formam redes que as religam, que as re-organizam. Isoladas pela competição, mas com fins que comungam entre si, essas empresas experimentam o que Manuel Castells chama de "paradoxo entre a rede e o ser". ${ }^{28}$

As redes podem tomar as mais diversas configurações. Há a junção de empresas para, por exemplo, enfrentarem o

${ }^{28}$ Castells, Manuel, A sociedade em rede, ob. cit., Vol. 1, 23. 
mercado mundial, com o é o caso dos pools de laranja brasileiros. ${ }^{29}$ Há os consórcios de empregadores que contratam trabalhadores rurais em conjunto ${ }^{30}$, ou, ainda, as redes de empresas comerciais que controlam a atividade de um sem número de outras empresas produtoras. Diante da atuação em rede, a divisão da economia em setores já não faz sentido, uma vez que, hoje, a maioria das atividades se concentra nos serviços prestados a outras empresas. ${ }^{31}$ As empresas com uma posição estrategicamente privilegiada no mercado são, via de regra, aquelas que, na rede, exercem seu poder de controlo, não pela participação no capital das demais, mas pelo poder de estipular as cláusulas contratuais que regem suas relações em rede. ${ }^{32}$

Como evidencia o exemplo dado no início do presente artigo, o desenvolvimento dos recursos tecnológicos permite também a organização do trabalho em redes mundiais. Se as grande empresas fordistas, organizadas como instituições, ainda necessitavam se instalar em unidades produtivas que tomavam seu espaço em grandes estabelecimentos, as empresas organizadas em redes toyotistas trabalham independentemente do local onde se instalam. Tirando proveito das possibilidades do tele-trabalho, pouco importa onde o trabalhador exerce suas atividades. Munido de instrumentos de trabalho de primeira linha da tecnologia da informática, fazem com que ele não escape do controlo do empregador, ou melhor, de quem contratou seus serviços. Se, no fordismo, os trabalhadores estão inseridos numa instituição, nas redes toyotistas fazem parte de uma organização. ${ }^{33}$ Essa organização, a rede, realiza alianças

\footnotetext{
${ }^{29}$ Mendes, Rodrigo Octávio Broglia, In médio stat virtus, cit. .

${ }^{30}$ Lemes, Viviane Aparecida, A figura jurídica do consórcio..., ob. cit..

${ }^{31}$ Castells, Manuel, op. cit., 251.

${ }^{32}$ Castells, Manuel, op. cit., 184.

${ }^{33}$ Coriat, Benjamin, Pensar pelo avesso..., ob.cit., 29ss.
} 
estratégicas entre empresas, não por último para externalizar os riscos da contratação de trabalhadores. ${ }^{34}$ Como Karl Marx já dizia, ao capital interessa separar o trabalho do trabalhador, pois o trabalho deve se tornar mercadoria. ${ }^{35}$ Fragmentando aquilo em que consistia o corpo dos trabalhadores coletivizados na empresa fordista, o capital organizado em rede, não por último, consegue desmantelar os sindicatos que encontravam nesse corpo seu princípio de organização.

\section{Atores coletivos globais e sua produção normativa}

Uma das características do direito global é o fato de que brota de várias fontes. Guardadas as devidas proporções históricas, a produção de normas jurídicas na esfera global lembra a teoria política de Antônio Gramsci, segundo a qual o agir político não está reservado apenas à esfera do poder público. Ao lado do Estado stricto sensu, isto é, seu aparato burocrático-repressivo, existe, na figura da sociedade civil, um Estado lato sensu, onde se travam as lutas hegemônicas pelo poder, onde se realiza a política, onde se decide o destino da sociedade. ${ }^{36} \mathrm{Na}$ globalização, os Estados, as comunidades de Estados e as organizações internacionais de direito público agem política - e juridicamente - ao lado dos atores de uma governança privada global, isto é, de redes

${ }^{34}$ Chesnais, François, op. cit., 104.

35 O trabalho", escreve Marx, "não repoduz somente mercadorias: produz a si próprio e o trabalhador como uma mercadoria na medida em que produz mercadorias.... O objeto que o trabalho produz, isto é, seu produto, retorna a encará-lo como um ser estranho, como um poder independente de seu produtor. O produto do trabalho é o trabalho que se fixa num objeto, tornou-se coisa, é a reificação do trabalho." MARx, Karl, Ökonomisch-filosofische Manuskripte aus dem Jahre 1844, cit., 511ss.

${ }^{36}$ Coutinho, Carlos Nelson, Gramsci..., cit.,119ss. 
empresariais, da Organização Mundial do Comércio, da International Standard Organization, de sindicatos mundiais e de organizações não-governamentais representantes de interesses difusos dos mais diversos. ${ }^{37}$

Assim, existe, no Direito do Trabalho, uma vasta gama de normas capazes de reger as complexas relações de trabalho em redes mundiais, cuja atividade independe, hoje, do lugar e da maneira como o trabalho é exercido. ${ }^{38}$ Embora de difícil aplicação, uma vez que carecem de sanções no caso de serem infringidos, os tratados internacionais elaborados pela Organização Internacional do Trabalho (OIT), as convenções internacionais do trabalho, constituem, desde 1919, uma base normativa para um direito do trabalho mundial. Ao lado de suas convenções, suas recomendações e a declaração de seus princípios são plataformas políticas que visam um mínimo de dignidade para os trabalhadores. E, embora a OIT não possua meios jurídicos para fazer valer suas normas, ela é uma instância política importante no cenário mundial, não por último, pelo seu banco de dados sobre o trabalho no mundo, pelas análises que faz desses dados e pela sua militância contra as verdadeiras chagas do mercado globalizado: o trabalho infantil e o trabalho escravo. ${ }^{39}$ Dentre as normas internacionais elaboradas na esfera internacional privada, destacam-se, sobretudo quando se trata de normas que visam garantir a segurança e a saúde no trabalho, as normas da International Standard Organization (ISO).

Ao lado das normas internacionais elaboradas tanto por organizações internacionais de direito público, quanto por organizações internacionais de direito privado, existem redes

37 Teubner, Gunther, “A Bukowina global...”, ob. cit., 9ss.

${ }^{38}$ Harvey, David, op. cit., 175.

${ }^{39}$ Hepple, Bob, Labour laws and global trade, cit., 25ss.; Palo Neto, Vito, Conceito jurídico..., cit.. 
de contratos transnacionais que constituem uma verdadeira lex mercatoria global, ou seja, um direito estatuído e praticado pelos agentes econômicos mundiais. Nas entrelinhas dos ordenamentos jurídicos nacionais e internacionais, as redes contratuais formam hierarquias de normas por contratos normativos, ao mesmo tempo que formam um sistema de controlo dessas normas e de seu comprimento por um sistema de arbitragem de alcance mundial. ${ }^{40}$ Os contratos praticados para regular a atividade econômica mundial podem ou não conter cláusulas sociais que visam garantir aos trabalhadores um mínimo de trato digno. Dentre os contratos negociados nessas redes, são dignos de nota, no âmbito do Direito do Trabalho, os acordos-marco transnacionais e os acordos coletivos transnacionais.

\section{Acordos-marco e acordos coletivos transnacionais: ensaios de negociação coletiva transnacional}

Vale a pena apresentar o relatório da Central Internacional das Organizações Sindicais Livres, única central sindical mundial, desde 2007. ${ }^{41}$ Segundo esse relatório, à organização em redes empresariais mundiais os sindicatos respondem pela formação de comitês de empresa, constituídos por redes formais ou informais de sindicatos de trabalhadores que atuam numa mesma empresa em vários países, constituindo uma "autêntica cooperação global". ${ }^{42}$ Situam-se ao lado dos comitês de empresa, institucionalizados em alguns países por lei

40 Teubner, Gunter, op. cit., 22ss.

${ }^{41}$ Confederación Internacional de Organizaciones Sindicales LiBres (CIOSL). Una guía sindical sobre la mundialización. 2.e. Disponível em http://www.icftu.org/pubs/globalisation

${ }^{42}$ Op.cit., 99. 
ou por convenção coletiva, e dos comitês de empresa europeus, previstos na Diretiva do Conselho de Ministros da União Europeia de 22 de Setembro de $1994 .{ }^{43}$ As federações sindicais internacionais têm um papel importante nessa articulação em rede, facilitada, por sua vez, pela tecnologia da informação. Assim, a Federação Internacional dos Trabalhadores em Indústrias Metalúrgicas já organizou comitês nas maiores empresas automobilísticas (General Motors, Ford, Volkswagen, Volvo, Fiat, Toyota, Nissan, Honda, Mitsubishi e Mazda), nas empresas do sector eletro-eletrônico (General Electric, Asea-Brown Boveri, Matsushita, Siemens, Electrolux e Thomson Multimedia), e em empresas da área da engenharia mecânica (SKF e Caterpillar). ${ }^{44}$

A par dessa formação de comitês sindicais nas empresas transnacionais, as federações sindicais internacionais negociaram, até hoje, cerca de 30 acordos-marco. Estes têm como partes, por um lado, empresas transnacionais (entre outras, a Accor, Danone, Faber Castell, Rhodia ${ }^{45}$ e, por outro lado, federações sindicais mundiais. ${ }^{46}$ Os acordos-marco interna-

${ }^{43}$ Op. cit., 101.

${ }^{44}$ Op. cit., 99.

${ }^{45}$ Uma relação detalhada desses acordos está no citado relatório da CIOSL, op. cit., 104.

${ }^{46}$ Existem, atualmente, as seguintes federações sindicais internacionais: FIP - Federación Internacional de los Periodistas; FITCM Federación Internacional de los Trabajadores en la Construcción y de la Madera; FITIM - Federación Internacional de Trabajadores de las Industrias Metalúrgicas; FITTVC - Federación Internacional de Trabajadores del Textil, Vestuario y Cuero; ICEM - Federación Internacional de Sindicatos de Trabajadores de la Química, Energía, Minas e Industrias Diversas; IE - Internacional de la Educación; ISP - Internacional de Servicios Públicos; ITF - Federación Internacional de Trabajadores del Transporte; UITA - Unión Internacional de Trabajadores de la Alimentación, Agrícolas, Hoteles Restaurantes, Tabaco y Afines; UNI 
cionais não se confundem com os chamados códigos de conduta, declarações unilaterais de algumas empresas (Bosch e Volkswagen, v.g.), que prometem respeitar os direitos contidos na Declaração Universal dos Direitos Humanos e em algumas convenções da Organização Internacional do Trabalho. Acordos-marco são documentos jurídicos, frutos de um conflito coletivo e da negociação coletiva. Vistos por um prisma político, apresentam um caráter bilateral, um caráter de "luta de classes" ou de "concertação social".

O que chama a atenção, no que se refere ao conteúdo dos acordos, é o seu caráter político. Trata-se, na maioria dos casos, de instrumentos de caráter declarativo, cuja intenção é salvaguardar as normas fundamentais que garantem a dignidade do trabalhador, elencadas pela OIT em sua Declaração de Princípios ou, ainda, pela Declaração Universal dos Direitos Humanos. Dentre os direitos mais citados destacam-se os direitos fundamentais coletivos, a abolição do trabalho forçado e do trabalho infantil e a prevenção contra a discriminação salarial, contidos nas Convenções 87, 98, 29, 105, 100, 111, 138 e 182 da OIT. ${ }^{47}$

Por seu caráter político, os acordos marco podem ser considerados um exemplo de produção normativa dos chamados private government regimes e da tendência global da politização do espaço privado. ${ }^{48}$ Nesse contexto, é importante frisar, como o faz a CIOSL, que, para garantir o cumprimento da maioria dos acordos, não há instâncias verificadoras ou fiscalizadoras, não há instâncias jurisprudenciais. O cumprimento dos acordos depende unicamente

- Union Network International. Confederação Internacional das Organizações Sindicais Livres, op.cit., 27.

${ }^{47}$ Op. cit., 105.

${ }^{48}$ Teubner, Gunther, "Regimes privados...”, cit., 105ss. 
dos esforços de organização e de mobilização dos próprios trabalhadores. ${ }^{49}$

Os acordos coletivos transnacionais têm um caráter menos declaratório e podem estatuir normas exigíveis e exeqüíveis. Um exemplo histórico de um acordo coletivo transnacional do trabalho é o acordo coletivo firmado, no ano de 2000, entre a Volkswagen, de um lado, e os Sindicatos dos Metalúrgicos de Santo André, São Bernardo do Campo, São Caetano do Sul, Diadema, Mauá, Ribeirão Pires e Rio Grande da Serra, do Brasil, e de Córdoba, da Argentina. O acordo é mais importante por seu aspecto teórico-jurídico do que por suas conseqüências práticas, uma vez que se trata do primeiro acordo coletivo do gênero que prevê o direito dos trabalhadores à estabilidade no emprego e a instituição de comissões de fábrica nos estabelecimentos da Volkswagen em Córdoba e no ABC paulista. $\mathrm{O}$ acordo contém, portanto, cláusulas normativas que regem diretamente os contratos individuais de trabalho e relações coletivas no local de trabalho.

\section{Reflexões finais}

Transpondo fronteiras, a negociação coletiva no cenário global traz para o Direito do Trabalho brasileiro algumas questões ligadas justamente a seus limites inerentes.

Em primeiro lugar, importa lembrar que os contratos normativos oriundos da negociação coletiva são limitados no tempo. Acordos e convenções coletivas têm uma data-base, em torno da qual, via de regra, se inicia uma nova negociação

49 Confederação Internacional das Organizações Sindicais Livres, op. cit., 105. 
que põe em xeque a conquista de direitos de outrora. Além disso, os contratos coletivamente negociados têm sua validade circunscrita no espaço, enquanto, como demonstra o caso narrado no início do presente artigo, o trabalho pode ser organizado em rede mundial e, portanto, atuar fora das fronteiras, dos limites do espaço e do tempo. ${ }^{50}$

Por outro lado, ao menos no que tange o direito brasileiro, os sindicatos mundiais não têm representatividade, uma vez que a Constituição Federal, em seu artigo 8. ${ }^{\circ}$ VI, obriga à participação dos sindicatos na negociação coletiva, além de, no art. $8 .^{\circ}$ III, colocar na mão destes a autonomia privada coletiva, isto é, o poder de estatuir normas nas convenções coletivas e nos acordos coletivos do trabalho. A lei magna brasileira prevê que as convenções ou acordos coletivos de trabalho sejam circunscritos à categoria ou à empresa no âmbito local, regional ou, no máximo, nacional. A validade de um acordo coletivo transnacional só se produz quando a empresa, de um lado, e o sindicato, de outro, têm representatividade no Brasil, tal como circunscrita pelo próprio art. $8 .^{\circ}$ da Constituição Federal.

Finalmente, a organização sindical brasileira carece de uma profunda revisão, uma vez que dificulta a representação dos interesses dos trabalhadores. Enquanto o capital se organiza em redes mundiais, os sindicatos brasileiros permanecem engessados numa lei que os mantém organizados segundo critérios espaciais. Enquanto a setorialização da economia se torna obsoleta, a lei segue a idéia da organização setorial expressa no conceito da "categoria".

No entanto, se permanecem essas contradições no ordenamento jurídico trabalhista brasileiro, os ganhos políticos

${ }^{50}$ A mudança da percepção do espaço e do tempo na pós-modernidade analisada por David Harvey na obra citada. 
da negociação coletiva transnacional são consideráveis. Sindicatos e centrais sindicais brasileiros participam nas redes de sindicatos que constituem os comitês de empresas transnacionais, são sócios das federações internacionais sindicais e, last not least, fazem parte do corpo da CIOSL. Trabalhadores brasileiros e argentinos descobriram que, a par das rivalidades no futebol, têm bandeiras de luta em comum e que seus sindicatos são capazes de carregar essas bandeiras.

A atuação das federações internacionais sindicais, a fusão das centrais sindicais mundiais numa única grande central, a organização de trabalhadores das mais diversas nacionalidades nos sindicatos alemães e franceses, para citarmos dois exemplos, e a solidariedade dos sindicatos norteamericanos com os trabalhadores imigrantes clandestinos oriundos dos quatro cantos do mundo evidenciam, talvez mais do que nunca, que é possível realizar o que, há 160 anos, dois jovens alemães, Karl Marx e Friedrich Engels sonharam para um dia se realizar, ou seja: "Proletários de todos os países, associem-se!" 
(Página deixada propositadamente em branco) 


\section{REFERÊNCIAS BIBLIOGRÁFICAS}

Adorno, Theodor W. \& Horkheimer, Max. Dialética do esclarecimento: fragmentos filosóficos. Rio de Janeiro: Zahar, 1985.

Agamben, Giorgio. Estado de exceção. Trad. Iraci Poleti. São Paulo: Boitempo, 2004.

Antunes, R. "A nova morfologia do trabalho e o desenho multifacetado das ações coletivas", In: Santana, M. A. \& RamaLHO, J. R. (orgs.) Além da Fábrica: trabalhadores, sindicatos e a nova questão social. São Paulo: Boitempo, 2003.

Antunes, Ricardo. Adeus ao Trabalho?: Ensaio sobre as metamorfoses $e$ a centralidade do mundo do trabalho. 2. ed. São Paulo: Cortez/Editora da Unicamp, 1995.

Baudirllard, Jean. Simulacros e simulação. Trad. Maria João da Costa Pereiria. Lisboa: Relógio d'Água, 1991.

Bauman, Zygmunt. Modernidade líquida. Trad. Plínio Dentzien. Rio de janeiro: Jorge Zahar, 2001.

Bourdieu, Pierre. O poder simbólico. 3. Ed. Trad. Fernando Tomaz. Rio de Janeiro: Bertrand Brasil, 2000.

Castells, Manuel. A sociedade em rede. Trad. Roneide Venâncio Majer. São Paulo: Paz e Terra, 1999. Coleção: A era da informação: economia, sociedade e cultura. Vol 1, 23.

Chesnais, François. A mundialização do capital. Trad. Silvana finzi Foá. São Paulo: Xamã, 1996.

Confederación Internacional de Organizaciones Sindicales Libres (CIOSL). Una guía sindical sobre la mundialización. $2^{a}$ ed., disponível em: http://www.icftu.org/pubs/globalisation

Coriat, Benjamin. Pensar pelo avesso: o modelo japonês de trabalho e organização. Trad. Emerson S. da Silva. Rio de Janeiro: Revan/ /UFRJ, 1994, 29ss. 
Coutinho, Carlos Nelson. Gramsci: um estudo sobre seu pensamento político. Rio de Janeiro: Civilização Brasileira, 2003.

Derrida, Jacques. Force de loi: Le fondement mystique de l'autorité. Paris: Galilée, 1994.

Forbes, Jorge. "A clínica do homem desbussolado", Falasser. Revista da Delegação Paraíba da EBP, n. 2 (2007), 31-49.

Forbes, Jorge. O princípio responsabilidade: do medo ao desejo. São Paulo: IPLA, 2008.

Forbes, Jorge. Você quer o que deseja? São Paulo: Bestseller, 2003.

Habermas, Jürgen. Der philosophische Diskurs der Moderne. $6^{\mathrm{a}} \mathrm{Ed}$. Frankfurt AM Main: Suhrkamp, 1998.

Harvey, David. Condição pós-moderna: uma pesquisa sobre as origens da mudança cultural. Trad Adail Ubirajara Sobral e Maria Stela Gonçalves. 7. ed. São Paulo: Loyola, 1998, 129.

Hepple, Bob. Labour laws and global trade. Oxford: Hart, 2005, 25ss..

Hobsbawm, Eric. Era dos extremos: o breve século XX, 1914-1991. Trad. Marcos Santarrita. São Paulo: Companhia das Letras, 1995, 223ss.

Lacan, Jacques. Des noms-du-père. Paris: Seuil, 2005.

Lemes, Viviane Aparecida. A figura jurídica do consórcio de empregadores rurais. São Paulo: LTr, 2006.

Lyotard, Jean-François. A condição pós-moderna. Rio de Janeiro: José Olympio, 1998, 69.

MarX, Karl. Ökonomisch-filosofische Manuskripte aus dem Jahre 1844. In: Marx, Karl \& Engels, Friedrich. Werke. Ergänzungsband. Berlin: Dietz, 1973, 511ss.

Mendes, Rodrigo Octávio Broglia. In médio stat virtus: Aussenhaftung virtueller Unternehmen. Magisterarbeit. Frankfurt: Johann Wolfgang Goethe Universität, Fachbereiech Rechtswissenschaft, 2002.

Miller, Jacques Alain \& Milner, Jean-Claude. Você quer mesmo ser avaliado?: entrevistas sobre uma máquina de impostura. Trad. Vera Lopes Besset. São Paulo: Manole, 2006.

Palo Neto, Vito. Conceito jurídico e combate ao trabalho escravo contemporâneo. São Paulo Ltr, 2008. 
Rотн, A.-N. "O direito em crise: fim do Estado moderno?" In: FARIA, J.E. et al. Direito e globalização econômica: implicações e perspectivas. São Paulo: Malheiros, 1998.

Rudiger, Dorothee Susanne. "O direito do trabalho brasileiro no contexto da globalização". Comunicações. Piracicaba, vol.5, n. ${ }^{\circ} 2$ (Jan. 2001), 165-170.

Rudiger, Dorothee Susanne. "Transformações do direito do trabalho na pós-modernidade: o exemplo Brasil". In: LiNDGReN Alves J.A. et alii. Direito e cidadania na pós-modernidade. Piracicaba: Editora UNIMEP, 2002.

Rudiger, Dorothee Susanne. "Sindicatos como atores globais: um desafio para o direito sindical brasileiro". In: LEAL, Mônia Clarissa Hennig et alii. Constitucionalismo social: o papel dos sindicatos na realização dos direitos sóciais em tempos de globalização. Porto Alegre: Verbo Jurídico, 2008.

Teubner, Gunther. "Regimes privados: direito neo-espontâneo e constituições dualistas na sociedade mundial". Trad. Dorothee Susanne Rudiger. In: Teubner, Gunther. Direito, sistema e policontexturalidade. Piracicaba: Editora UNIMEP, 2005, 105ss.

Teubner, Gunther. "A Bukowina global: sobre a emergência de um pluralismo jurídico transnacional". Impulso, Piracicaba, vol 14, n. ${ }^{\circ} 33,2003$.

Thompson, Edward Paul. "Time, work-discipline, and industrial capitalism". Past and Present. n. 38 (Dez/1967), 57-97.

TOURAINE, Alain. Um novo paradigma: para compreender o mundo de hoje. Trad. Gentil Avelino Titton. Petrópolis: Vozes, 2006.

Dorothee Susanne Rüdiger Professora do Curso de Mestrado da Universidade Metodista de Piracicaba, Brasil 